\title{
Nachruf zum Tod von Anna Halprin
}

\author{
Ursula Schorn
}

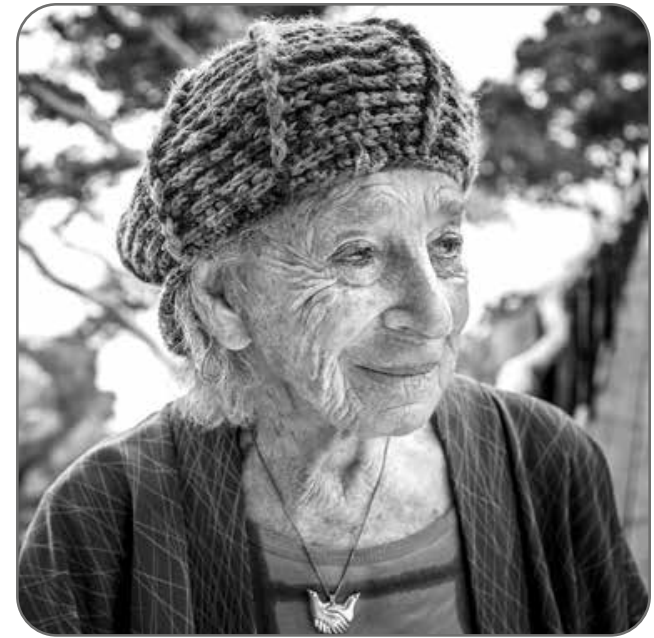

Abb. 1: Anna Halprin

Foto: Tamalpa Institute, San Rafael

n diesem Jahr erreichte uns die Nachricht von Anna Halprins Tod. Hundert Jahre hat sie auf dieser Erde gelebt und gewirkt als Tänzerin, Choreographin und Pädagogin. Sie hat zahlreiche Spuren hinterlassen, von der Tanzkritikerin Dorion Weickmann anlässlich ihres 100. Geburtstags in besonders treffender Form in Worte gefasst: „Eine wie sie bräuchte es jetzt. Eine, die friedfertig protestiert und trotzdem jede Menge Aufsehen erregt. Eine, die Wildfremde vergemeinschaftet und jedermanns Eigenheiten respektiert. Eine, die Menschen zum zärtlichen Umgang mit Hinfälligkeit ermutigt, zu Berührung und Umarmung. Die Tänzerin Anna Halprin, Vordenkerin der postmodernen Choreografie, ist schon Community Coach gewe- sen, ehe es das Wort überhaupt gab.“ (Weickmann 2020)

Anna Halprin, anlässlich ihres Todes international gewürdigt, hat die konventionell definierten Grenzen zwischen Kunst, Pädagogik, Therapie und politischen Aktionen immer wieder überschritten. Ihre Intention, Veränderungen auf persönlicher und sozialer Ebene zu bewirken, hat zu radikalen Konsequenzen geführt, die sie nach Esalen in Fritz Perls' gestalttherapeutische Gruppen brachte. Dort war sie auf der Suche nach Wegen, Motion und Emotion, Leben und Kunst im Tanz miteinander zu verbinden. Ihre Krebserkrankung führte sie zu einer tiefgreifenden Erkenntnis, die sie mit ihren Worten so beschreibt: „Before I had cancer, I lived my life for the arts, after cancer, I lived my art for my life.“ Ein Perspektivenwechsel, den sie am eigenen Leibe und in ihrer Arbeit mit Krebserkrankten vollzog. In den $1980 e r$ Jahren widmete sie sich von AIDS Betroffenen und choreographierte Rituale, die den von ihrem Mann Lawrence Halprin entwickelten Prinzipien kollektiver Kreativität folgten. Der Film „Breath made visible“, eine Dokumentation ihres Lebens und Wirkens, gibt einen Einblick in ihr beeindruckendes Leben. Es ist Zeit, ihre Impulse wahrzunehmen, besonders in unserer Zeit jetzt, in der das Phänomen des „Disembodiments“, des Verlustes von Kontakt und leiblicher Präsenz, tiefe Spuren weltweit auf der körperlichen, emotionalen und sozialen Ebene hinterlässt.

Und nicht zu vergessen, dass Anna Halprin als jüdische Tänzerin ein tiefes Anliegen in die 


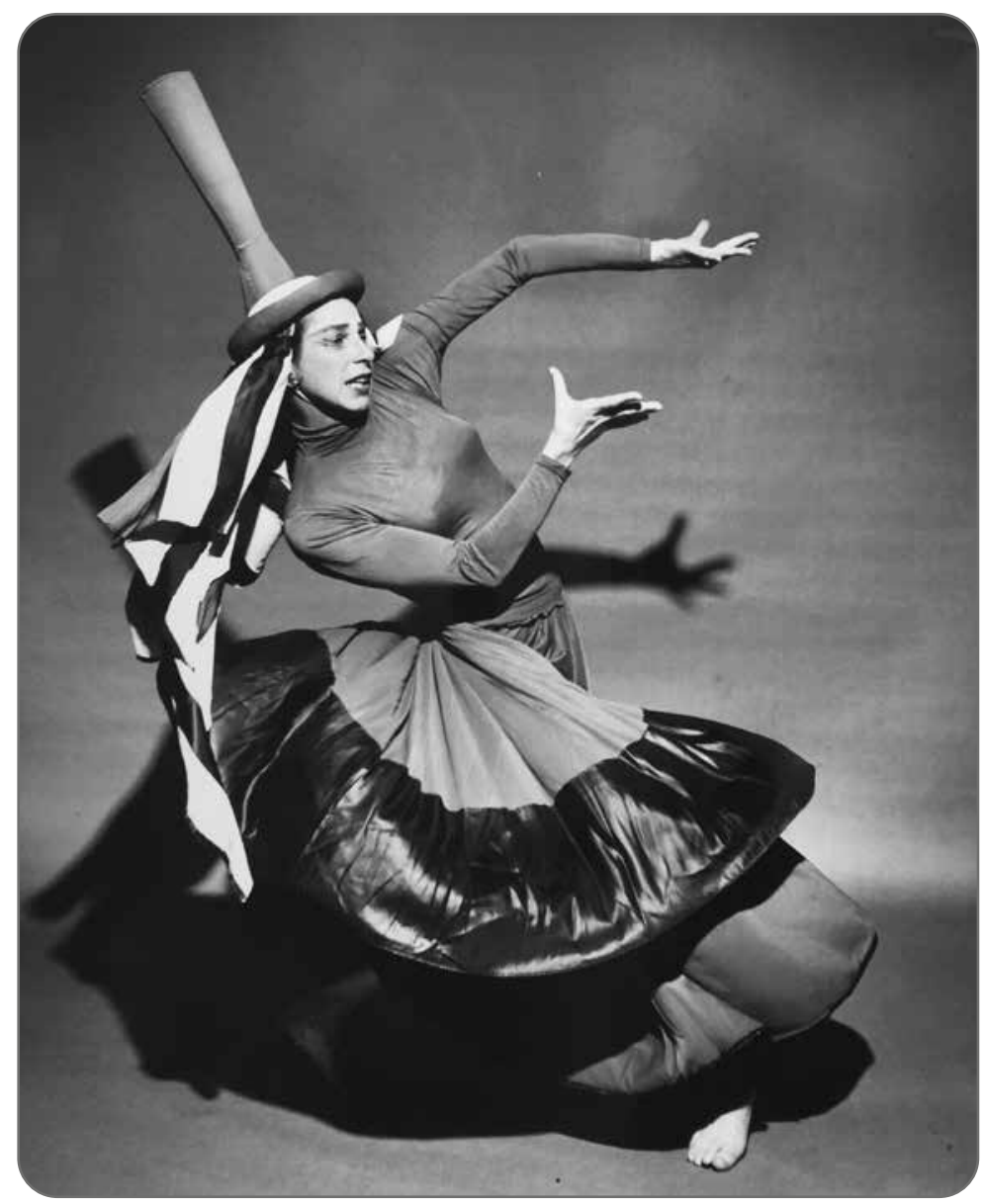

Abb. 2: Anna Halprin in

"The Prophetess“ (1955)

Foto: Tamalpa Institute,

San Rafael

Welt getragen hat mit ihren Worten: „May dance once again become a healing art.“

Das Buch über Anna Halprins Leben und Wirken „Anna Halprin. Tanz - Prozesse - Gestalten“ von Gabriele Wittmann, Ursula Schorn und Ronit Land wird demnächst in 3. Auflage erscheinen.

\section{Literatur}

Weickmann, D. (2020): Vordenkerin des postmodernen Tanzes, Vorbild im friedlichen Kampf für Bürgerrechte: Die Choreografin Anna Halprin wird hundert Jahre alt. Süddeutsche Zeitung vom 13.7.2020. In: https://www.sueddeutsche. de/kultur/ein-idol-feiert-geburtstag-wipfel-derkunst-1.4964685, 27.6.2021 